\title{
Hysterotomy- Indications and Associated Complications: An Indian Teaching Hospital Experience
}

\author{
Siwatch S, Sehgal A, Goyal LD \\ Department of Obstetrics and Gynecology, PGIMER, Chandigarh, India
}

\begin{abstract}
Aims: To analyze the incidence, indications, period of gestation and associated morbidity and mortality of hysterotomy in a tertiary care hospital in India.
\end{abstract}

Methods: Ten year inpatient records of abortions and hysterotomies at a tertiary care government teaching hospital in North India were reviewed and analyzed.

Results: The incidence of hysterotomy at our institute was $1.1 \%$ of all abortions. Fifty two hysterotomies were performed. Majority of the women were multigravidas and in the second trimester of pregnancy. Haemorrhage due to placenta previa was the commonest indication for surgery. Failed induction for medical termination of pregnancy (MTP) and previous caesarean were the other common causes. Hysterotomy was associated with considerable morbidity.

Conclusions: Abortion in any trimester may be associated with need for surgical intervention which may be associated with serious morbidity.

Key words: Abortion, hysterotomy, obstetric surgical procedures

\section{INTRODUCTION}

Hysterotomy is an incision opening that opens the endometrial cavity usually via abdominal route for completion of procedure of abortion. With the wide use of medical methods of second trimester abortion, hysterotomy is seldom required as an elective procedure. ${ }^{1}$ However, it may be indicated in certain situations like hemorrhage in second trimester and failed induction, especially with the increase of patients with previous uterine surgeries. There is paucity in literature on the incidence, indications and associated morbidity of the surgery.

\section{CORRESPONDENCE}

Dr. Sujata Siwatch, MD, MPH

Department of Obstetrics and Gynecology

PGIMER, Sector-12, Chandigarh

Phone: 9888789672

Email: siwatch1@yahoo.com
The aims of our study were 1) to look at the incidence of hysterotomies in a tertiary care teaching hospital in North India 2) to analyze the indications and period of gestation of performing hysterotomy and 3 ) to study the morbidity and mortality associated with hysterotomies.

\section{METHODS}

Retrospective analysis of 10 year inpatient data (January 2000- December 2010) was performed at Government Medical College, Chandigarh, India which is a tertiary care government teaching hospital. The data was studied for the parity of the women, period of gestation, indications and complications of hysterotomies. Statistical analysis 
was done using simple percentage. For the study, all evacuations conducted upto 26 weeks of gestation were considered as we have practically no salvagability till this period of gestation.

\section{RESULTS}

A total of fifty two hysterotomies were performed in the institute over a period of ten years making a rate of $1.1 \%$ of all abortions (52 of 4592 ) and $3.8 \%$ of all mid trimester abortions (49 of 1257).

Table 1. Demographic features of the women who underwent hysterotomy

\begin{tabular}{llllll}
\hline $\begin{array}{l}\text { Age in } \\
\text { Years }\end{array}$ & No & $\begin{array}{l}\text { Parity } \\
\text { before } \\
\text { index } \\
\text { pregnancy }\end{array}$ & No. & $\begin{array}{l}\text { Period of } \\
\text { gestation }\end{array}$ & No \\
\hline$<20$ & 2 & Nullipara & 7 & $<12$ & 2 \\
$21-25$ & 17 & Primipara & 13 & $12-15$ & 9 \\
$26-30$ & 18 & Para 2 & 14 & $15-20$ & 16 \\
$31-35$ & 11 & Para 3 & 11 & $21-26$ & 25 \\
$>35$ & 4 & Para 4 & 7 & & \\
\hline
\end{tabular}

Table 1 shows the distribution of age, parity and period of gestation of these women. The majority of the women were between 20-35 years of age. Though most women were multiparous (61.5\%), a number of primiparous and primigravida women also underwent hysterotomy. Ninety four percent of hysterotomies were done in the second trimester of pregnancy, most being between 20-25 weeks period of gestation. All the abortions above twenty weeks pregnancy were spontaneous in onset, twenty weeks being the legal upper limit for abortion in our country. There were also three cases of first trimester hysterotomies (5.7\%), detailed in Table 2.

Table 2. Indications for the hysterotomies performed from Jan 2000- Dec 2010 at Government Medical College \& Hospital, Chandigarh

\begin{tabular}{|c|c|c|}
\hline Time & Iadiation & $\mathrm{Na}$ \\
\hline \multirow[t]{4}{*}{ Is tinester } & Lastity to nequtiate intendl os & $3(1$ each $)$ \\
\hline & 1. Perfantion & \\
\hline & 2. Severe cerviad stensis & \\
\hline & 3. Pheicus 3LSCS & \\
\hline \multirow[t]{9}{*}{ Ind trimeser } & Low lyng plexente & 29 \\
\hline & Arevious 2 LSCS & 7 \\
\hline & Failed istuction & 7 \\
\hline & Hear bisase with sersinity o bepuris & 1 \\
\hline & Previsus repait of ropure scar & 1 \\
\hline & Tubal lgetixe faltuse & 1 \\
\hline & Conjuited wins & 1 \\
\hline & 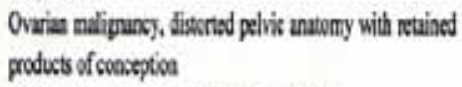 & 1 \\
\hline & Sapeced ngture with peibseal colsction & 1 \\
\hline
\end{tabular}

LSCS= low segment caesarean section
The commonest indication of hysterotomy was bleeding per vaginum due to low lying placenta followed by termination of pregnancy in women with previous two cesarean sections and failed induction for medical termination of pregnancy in seven cases each (Table 2). Of the cases of failed medical termination of pregnancy, combinations of inducing agents like mifepristone and misoprostol, cervigel, ethycridine acetate instillation and oyxtocin were used as inducing agents in these patients before resorting to hysterotomy, the interval from induction to decision for surgical termination varying from 60-72 hours. In two patients with previous scarred uterus complicated with eclampsia and prolonged rupture of membranes respectively, attempts of induction were prematurely decided in favor of hysterotomy. Other miscellaneous indications were: a patient with mechanical prosthetic heart valves, history of deep vein thrombosis and sensitivity to heparin who underwent elective hysterotomy to reduce the time off anticoagulants; Medical termination of pregnancy (MTP) in a previous repaired rupture uterus; a primigravida who refused destructive procedure on conjoined twins; a multigravida with failed tubal ligation opting for surgical termination of pregnancy with salpingectomy; a patient with ovarian malignancy who desired termination of pregnancy and chemotherapy and a patient with suspected rupture uterus turned out to be couvelaire uterus at laparotomy.

During first trimester MTP, inability to negotiate the cervical os in three patients- with posterior perforation just above the internal os, severe cervical stenosis and a patient with history of previous three cesarean sections required hysterotomy.

Nineteen patients had had uterine surgeries previouslyeleven of these patients had two previous cesarean sections, five with previous one cesarean section, one had previous hysterotomy scar and one had previous repair of ruptured uterus. Thirteen patients had previous dilatation and curettage done for pregnancy related complications. Thirty patients underwent concomitant bilateral tubal ligation with hysterotomy. The need for tubal ligation favored hysterotomy in most of these cases. Low transverse incision was made on uterus for better scar healing and reduced chances of rupture in subsequent pregnancies, except in six patients. In all these patients, concomitant tubal ligation had been done.

Table 3 shows the list of various complications encountered in patients who underwent hysterotomy. The indications for the hysterotomy itself were responsible for the majority of the complications. Three patients of placenta accreta required hysterectomy for uncontrolled hemorrhage. In all three patients, placenta accrete was confirmed on histopathology. Two patients developed disseminated intravascular coagulation, one presented with massive abruption and couverlaire uterus and the second had 
massive hemorrhage due to low lying placenta. One patient with previous two cesarean section suffered gut injury, one required ventilatory support for acute respiratory distress, one patient each developed prolonged post operative febrile illness and paralytic ileus. Thus, hysterotomies were associated with a morbidity of $17 \%$ and serious morbidities (defined as need for unexpected surgeries and prolonged febrile illness) in $9.6 \%$ patients. Multiple blood transfusions were required in cases with antepartum bleeding. There was no mortality. Mean hospital stay was 7.4 days.

Table 3. Complications associated in patients who underwent hysterotomy

\begin{tabular}{ll}
\hline Complications associated with hysterotomy & No. \\
\hline Hysterectomy & 3 \\
Acute respiratory distress & 1 \\
DIC & 2 \\
Gut injury & 1 \\
Febrile illness & 1 \\
Paralytic ileus & 1 \\
\hline
\end{tabular}

$D I C=$ disseminated intravascular coagulation

\section{DISCUSSION}

Hysterotomy, though rarely used, may seldom be required for completion of abortion, in second and even first trimester. ${ }^{1}$ The indications in our study included low lying placenta, failed induction for medical termination of pregnancy and previous caesarean section. Today, with increasing numbers of caesarean sections and better prenatal diagnostic techniques, more women with previous scarred uterus desire termination of pregnancy in the second trimester. However, literature on safety of use of medical methods of mid trimester termination of pregnancy in previously scarred uterus is limited. ${ }^{2}$ Goyal et al, in a systematic literature review, calculated a uterine rupture rate of $0.04 \%$ in intact and $0.2 \%$ rate in scarred uterus in second trimester misoprostol induced abortions. ${ }^{3}$

Goldstein reported a considerable morbidity rate associated with hysterotomy. ${ }^{4}$ The rate of morbidity in our study is $17 \%$. Efficacious medical methods of mid trimester abortion have low complication rates and are commonly used today. However, in case of failure of medical method of termination of pregnancy or where there is need for surgical evacuation of second trimester pregnancy, other methods of mid trimester abortions, especially dilatation and evacuation, are reported with a considerable lower complication rate. ${ }^{5,6}$ Though the use of dilatation and evacuation for second trimester abortion is common in the countries like United States and England, the procedure is not very commonly practised in India as in some other parts of the world due to lack of needed equipment and training. ${ }^{7-10}$ There is little literature on scar integrity of previous hysterotomy incisions. ${ }^{11}$ As the lower uterine segment is not well formed in the first and second trimesters, there is a greater chance of uterine incision being placed in the upper uterine segment, compromising the scar strength. ${ }^{12}$ Nevertheless, we advocate a horizontal incision in the region of the lower uterine segment. Apart from this, previous scarred uterus also predisposes to placenta previa and morbidly adherent placenta. Two of the patients who underwent hysterotomy required hysterectomy for placenta accreta in their subsequent pregnancies in our own institute. Thus, an ultrasound must be done to determine the placentation so that placenta accreta and need for hysterectomy may be anticipated in patients with low lying placenta.

The retrospective design of our ten year study makes it difficult to elaborate reasons for undertaking hysterotomy in women with previous scarred uteri, reasons for using vertical uterine scar in few patients and whether the decision of concomitant tubal ligation influenced the decision for hysterotomy. The reasons for the use of vertical rather than horizontal uterine incision could include lower uterine segment not being well formed, the non approachability of lower uterine segment and adhesion of bladder to previous scarred uterus. Our study is limited by differing skills of surgeons in a teaching training hospital, by confounding of various factors contributing to complications in patients undergoing hysterotomy for termination of pregnancy and the lack of follow up. Larger multi-centric prospective studies with long term follow up are needed to study the complication rates, scar integrity and management of future pregnancies of women undergoing hysterotomy.

\section{CONCLUSIONS}

Abortion in any trimester may be associated with need for surgical intervention. Hemorrhage due to low-lying placenta and previously scarred uteri are important indications for hysterotomy. Hysterotomies may be associated with considerable morbidity. The scar of hysterotomy has almost similar complications possible as with low segment cesarean section. The scar integrity in previous hysterotomy uterus needs to be studied.

\section{REFERENCES}

1. Kulier R, Fekih A, Hofmeyr GJ, Campana A. Surgical methods for first trimester termination of pregnancy. Cochrane Database of Syst Rev. 2001, Issue 4. Art. No.: CD002900. DOI: 10.1002/14651858. CD002900.

2. Lalitkumar S, Bygdeman M, Gemzell-Danielsson K. Mid-trimester induced abortion: a review. Hum Reprod Update. 2007;13(1):37-52.

3. Goyal V. Uterine rupture in second-trimester misoprostol-induced abortion after cesarean delivery: a systematic review. Obstet Gynecol. 2009;113(5):1117-23.

4. Goldstein P, Stewart G. Trends in therapeutic abortion in San Francisco. Am J Public Health. 1972;62(5):695-9. 
5. Grimes DA, Schulz KF. Morbidity and mortality from second-trimester abortions. J Reprod Med. 1985;30(7):505-14.

6. Lohr PA, Hayes JL, Gemzell-DanielssonK. Surgical versus medical methods for second trimester induced abortion. Cochrane Database of Syst Rev. 2008, Issue 1. Art. No.: CD006714. DOI: 10.1002/14651858.CD006714.pub2.

7. Government Statistical Service. Abortion statistics, England and Wales: 2005. Statistical Bulletin 2006/01 July 4, 2006.

8. Strauss LT, Herndon J, Chang J, Parker WY, Bowens SV, Berg CJ. Abortion surveillance--United States, 2002. Morbidity and Mortality Weekly Report. 2005;54:1-31.
9. Grimes DA. The choice of second trimester abortion method: evolution, evidence and ethics. Reprod Health Matters. 2008;16(31 Suppl):183-8.

10. Lewit S. D \& E midtrimester abortion: a medical innovation. Women Health. 1982;7(1):49-55.

11. Heys RF. Pregnancy after hysterotomy. Br Med J. 1973;1(5854):681-2.

12. Clow WM, Crompton AC. The wounded uterus: pregnancy after hysterotomy. Br Med J. 1973;1(5849):321-3. 